\title{
The Relationship between Experience of Negative Emotion, Emotional Regulation Strategies and Moral Judgment of College Students Shengli Chen
}

Luohe medical college

\begin{abstract}
Keywords: Experience of negative emotion ; Emotional regulation strategies; Moral judgment; College students.
\end{abstract}

\begin{abstract}
The study examined the relationships between the negative emotional experiences, emotion regulation strategies and moral judgment of college students. The results showed that subjects express more anger and less sadness during the test process. As to adjustment of the two negative emotions, relative more passive emotional regulation and instrumental strategies and less proactive emotional regulation were used by the students. Meanwhile, in following researches of moral judgment on injury by personal force, two-factor analysis of variance was used to compare the effect of negative intentions and non-utilitarian. By linear regression analysis and logistic regression analysis, more boys than girls tended to accept personal injury with neutral intentions. And personal injury with negative intention should be accepted by students with negative emotion of sadness, in light of utilitarian moral judgments. When students had few negative emotional experiences, their moral judgments tend to base on non-utilitarian.
\end{abstract}

\section{Introduction}

During the daily interpersonal communication, the college students often experience a variety of negative emotions, such as anger, sadness, disgust and fear, etc. Negative emotion regulation strategies of different students are different which lead to their different social adaptability. The power of emotion and people trying to adjust and control the emotion are common and indispensable in daily life. Among the accumulating researches focusing on emotion and emotion regulation strategies, Blanchard-Fields's (2008) method is perfect which divided the emotion regulation strategies based on behavioral self regulation model, stress coping and problem solving model. He divides the emotion regulation strategies into 3 categories, the purpose of problem solving strategy, the passive emotion regulation strategy and the active emotion regulation strategy; each kind of regulation strategy has the explicit operational definition[1].

College student emotional experience and emotional regulation strategy are not only closely related with their maturing personality characteristics, but also related with their social adaptation and mental health. The university period is an important period for the students to form their life and value views. Forming correct moral view and learning to carry on the moral judgment objectively and accurately are the essential part for forming the life and value views. According to previous studies (Greene, 2004), the moral judgment process can be divided into moral judgment of cognitive process and moral emotion judgment process; and the moral judgments can be divided to utilitarianism moral judgment and non utilitarian moral judgment [2]. Greene et al. (2009) also found that utilitarian moral judgment have different focuses based on the injury results caused by personal strength or not by personal strength. If the injury results are not caused by personal strength, the tests are cline to carry on utilitarian moral judgment while if the injury results are caused by personal strength, the tests are cline to carry on non utilitarian moral judgment[3].In the traditional utilitarian moral judgment, it is often highlight whether or not the result of personal power causes damage to this factor. Although the belief, desire, intention and causal attribution are also involved in the traditional utilitarian moral judgment, they are not highlight, or the differentiation is not clear. Therefore, in this study, we specifically set up the story of the content of the statement and highlight the intention of information, and explore the relationship between them in utilitarian moral judgment. 


\section{Method}

Subjects. We randomly selected 32 students in universities and colleges in Luohe, aged 17 to 24 years old, $\mathrm{M}=19.44, \mathrm{SD}=1.24$, including 5 males, 27 females. Analysis of all subjects by the statistical data, indicating all the subjects have the normal communicating skills in both spoken word expression ability and the ability to understand.

\section{Measurement Methods and Procedures.}

The Measurement of Emotion experience and Emotion regulation Strategies

On emotional experience and emotional regulation strategies for measurement mainly adopts interview method, the subjects were asked to recall three daily interpersonal problem during the past year, their emotion experience of anger and sadness during dealing with these interpersonal problems and how they regulating their emotions. Two encoding researchers encoded the recording of encoding. And the two encoding researchers solve the un-consistent encoding by discussion and consultation.

Measurement of Moral Judgment

Experimental design and procedures

The story task and grade judgments method (Greene, 2009) [3] were used and the experimental design as followed: the 2 (non / personal power: A1 injury results caused by non personal power, A2 injury results caused by personal power X 2 (intention: B1 negative intention B2 vs. neutral intention). The story was presented to the subjects on the paper and the subjects were required to give answers according to the instructions.

\section{Material}

Four different stories were produced by the combination of the intention and the level of the individual strength. Each subject was required to read 4 different stories (Attachment 1), and the sequences of story were random arranged.

Statistical Analyses. The correlation analysis and regression analysis were carried out by using SPSS11.5.

\section{Results}

Statistical Analyses of the Grief, Anger Experience and Emotion Regulation Strategies.Statistical analyses show that the subjects had more angry emotion experiences but less sad emotion experiences. And the subjects adopted passive regulation strategy and the problem solving strategy more frequently than active regulation strategy to adjust the negative emotions mentioned above (Table 1.)

Table 1 Statistical analyses of the grief, anger experience and emotion regulation strategies $(N=32)$

\begin{tabular}{ccccc}
\hline & Min & Max & M & SD \\
\hline Anger & 1.00 & 3.00 & 2.469 & 0.621 \\
sadness & 0.00 & 3.00 & 0.594 & 0.798 \\
$\begin{array}{c}\text { Problem } \\
\text { resolution } \\
\text { Active }\end{array}$ & 1.00 & 1.78 & 1.274 & 0.251 \\
$\begin{array}{c}\text { adjustment } \\
\text { Passive } \\
\text { adjustment }\end{array}$ & 1.00 & 1.56 & 1.173 & 0.169 \\
\hline
\end{tabular}

\section{Descriptive Statistics of Utilitarian Moral Judgment and Non-utilitarian Moral Judgment}

Statistical analyses in Table 2 showed that the number of participants, which were involved in the tests of Utilitarian and non-utilitarian moral judgment, under the situations of four different stories. Participants tested in Story 3 tended to perform non-utilitarian moral judgment, while others tested in Story 1, 2 and 4, tended to utilitarian moral judgment. 
Table 2 Descriptive statistics of Utilitarian moral judgment and non-utilitarian moral judgment tested $(N=32)$

\begin{tabular}{lcccc}
\hline number & Story 1 (A1B1) & story 2 (A1B2) & story3 (A2B1) & story4 (A2B2) \\
\hline $\begin{array}{l}\text { Utilitarian } \\
(\text { able })\end{array}$ & 24 & 30 & 14 & 26 \\
$\begin{array}{c}\text { non-utilitaria } \\
\text { (disable) }\end{array}$ & 8 & 2 & 18 & 6 \\
\hline
\end{tabular}

\section{Descriptive Statistical Analyses of Moral Judgment under the Situation of Four Different Stories}

Table 3 Descriptive Statistical analyses of moral judgment under the situation of four different stories $(N=32)$

\begin{tabular}{llrrr}
\hline & Min & Max & M & SD \\
\hline A1B1 & 0 & 7 & 2.94 & \\
A1B2 & 0 & 7 & 4.03 & 1.769 \\
A2B1 & 0 & 7 & 1.88 & 2.352 \\
A2B2 & 0 & 7 & 3.44 & 2.078 \\
\hline
\end{tabular}

As shown in Table 3, judgments were performed under 4 different Story contexts according to the scales of 7 point rating, in which the the larger numbers represents the more tendency for the participants' behaviors to be accepted. The ranks for judgment tested in story 3 were lower, while those others in Story 1, 2 and 4 were higher

Linear Regression and Logistic Regression Analyses of Relationship among Emotional Experiences, Emotion Regulation Strategies and Moral Judgment.

Related Analyses of Emotional Experiences, Emotion regulation Strategies and Moral Judgment

Table 4 shows the related results using Pearson analysis for sex, emotional experiences, emotion regulation strategies and moral judgment. We found that the abilities to experience sadness showed a significant negative correlation with moral judgment of utilitarianism or non-utilitarianism in story 3 , as well as rating of moral judgment under the situation of story A2B1. A negative correlation was also found between sex and moral judgment under the situation of story A2B2. However, no significant association was found between 3 emotional regulation strategies and moral judgment. 
Table 4 the relationship of emotional experiences, emotion regulation strategies and moral judgment

\begin{tabular}{|c|c|c|c|c|c|c|c|c|c|c|c|c|c|}
\hline & anger & story 1 & $\begin{array}{l}\text { A1 } \\
\text { B1 }\end{array}$ & story2 & $\begin{array}{l}\text { A1 } \\
\text { B2 }\end{array}$ & story3 & $\begin{array}{l}\text { A2 } \\
\text { B1 }\end{array}$ & story4 & $\begin{array}{l}\text { A2 } \\
\text { B2 }\end{array}$ & $\begin{array}{c}\text { Problem } \\
\text { Resolutio } \\
\text { n }\end{array}$ & Passive & $\begin{array}{c}\text { Initiativ } \\
\mathrm{e}\end{array}$ & sex \\
\hline 悲伤 & $\begin{array}{l}-.31 \\
9\end{array}$ & .023 & .178 & $\begin{array}{l}-1.9 \\
5\end{array}$ & .147 & $-.376^{*}$ & $.368 *$ & .045 & -.084 & -.070 & .087 & -.151 & .216 \\
\hline 愤怒 & & $\begin{array}{l}-.08 \\
9\end{array}$ & .043 & .224 & .104 & .058 & -.025 & $\begin{array}{r}-.23 \\
7\end{array}$ & .311 & -.001 & .049 & -.185 & -.092 \\
\hline story1 & & & $\begin{array}{l}-.745 * \\
*\end{array}$ & .149 & -.093 & .218 & $\begin{array}{r}-.31 \\
2\end{array}$ & $\begin{array}{r}-.09 \\
2\end{array}$ & -.123 & .171 & -.158 & -.265 & .050 \\
\hline A1B1 & & & & $\begin{array}{l}-.16 \\
3\end{array}$ & $.395 *$ & $\begin{array}{l}-.495 * \\
*\end{array}$ & $.621 * *$ & .154 & .120 & .012 & .027 & -.063 & -.239 \\
\hline story2 & & & & & $\begin{array}{l}-.598 * \\
*\end{array}$ & .228 & -.209 & $\begin{array}{r}-.12 \\
4\end{array}$ & .008 & .178 & -.190 & -.097 & .111 \\
\hline A1B2 & & & & & & -.274 & .265 & $\begin{array}{r}-.00 \\
9\end{array}$ & .242 & -.141 & .037 & -.019 & -.141 \\
\hline story3 & & & & & & & $-.918 * *$ & .101 & -.058 & .044 & -.049 & .205 & -.033 \\
\hline $\mathrm{A} 2 \mathrm{~B} 1$ & & & & & & & & $\begin{array}{r}-.04 \\
3\end{array}$ & .005 & -.062 & .077 & -.241 & -.023 \\
\hline story4 & & & & & & & & & $\begin{array}{r}-.807 * \\
*\end{array}$ & .079 & -.095 & -.020 & .207 \\
\hline A2B2 & & & & & & & & & & -.190 & .167 & -.050 & $-.371 *$ \\
\hline $\begin{array}{l}\text { Problem } \\
\text { Resolutio } \\
\text { n }\end{array}$ & & & & & & & & & & & $\begin{array}{r}-.760 * \\
*\end{array}$ & -.145 & -.219 \\
\hline Passive & & & & & & & & & & & & -.151 & $\begin{array}{l}.078 \\
10\end{array}$ \\
\hline Initiativ & & & & & & & & & & & & & 4 \\
\hline sex & & & & & & & & & & & & & \\
\hline
\end{tabular}

Logistic Regression Analyses of Emotional Experiences, Emotion Regulation Strategies and Moral Judgment

To further investigate the impacts of sex, anger and sadness experiences to Utilitarian moral judgment and non-utilitarian moral judgment, we performed regression analyses. Regression equations were achieved according the dependent variables of judgment rating scales under the situations of Story A2B1 and A2B2, as well as the independent variable of sex, student cadre experiences, anger, and sadness emotion experiences. The results revealed that sadness emotion experiences could markedly predict the judgment rating scales under the situations of Story A2B1 $(p<0.05)$, while the sex factor could predict those under the situations of Story A2B2 $(p<0.05)$.

To established logistic regression analyses, we used moral judgment of utilitarianism or non-utilitarianism in story 3 as the dependent variable, and sex, anger and sadness emotion experiences as independent variables. The results showed that emotion experiences could significantly predict the moral judgment of utilitarianism or non-utilitarianism in story $3(p<0.05)$ 。

\section{Discussion}

This study shows that the anger of college students is much higher than sadness. This conclusion is consistent with previous studies. Birditt (2005) study shows that adolescents report higher strength and longer-lasting anger,in stress scenario of social interaction with peers [4].When these young people who are in 17-24 year old compared with the elderly, they have problems more easily irritable, less calm, easy to clash with others, so the experience more anger. In addition, the subjects when processing negative emotion use passive emotional regulation and instrumental strategies more, use less proactive emotional regulation. Shuliang Mo, Kui Sun et al. (2011) research negative emotional regulation of young and old, and find that the younger group use instrumental strategies less, use proactive emotional regulation and passive emotional regulation more[5].Differences between conclusions are most likely because the subjects in this study are medical students. They have learned to treat patients required to be patient, careful, attentive, prompting them in dealing with the 
emotional, less use of proactive emotional regulation. So they fewer ask people who caused problems to vent their emotions.

During the utilitarian moral judgments and non-utilitarian moral judgments, the study highlights the intention and personal force. The results show that in the 3 story which highlights the negative intentions and personal force to cause harm to the results,subjects are more non-utilitarian moral judgments which don't agree to sacrifice one's life to save the lives of more people.In Story 1, story2, story 4, subjects were more utilitarian moral judgments. This result enriches the Greene et al. (2004) findings, they believe that in the result of impersonal forces caused injury situation, subjects tend to be utilitarian moral judgments; in situation of personal forces caused injuries result, subjects are more likely to be non-utilitarian judgment [2].In this study, when the personal force caused harm results and highlighting the neutral intent, participants tend to the utilitarian moral judgments.So the intent of hero and personal force is equally important in moral judgments.

In previous studies, the intent is an essential factor in the cognitive process of moral judgment (Cushman, 2008)[6]. Whether to use personal force may cause utilitarianism and non-utilitarian moral judgments, rather than non-utilitarian moral judgments activate mostly automatic emotional reactions related brain areas.Thus, we can see the interplay of moral judgment cognitive processes and emotional process by combining intent with personal force.Competition between these two processes can be further verified by FMRI technology, which can also become a direction of our future research.

The major highlight of this study is that combine emotional experience, emotional regulation strategies with moral judgment. By linear regression analysis and logistic regression analysis, the study shows that more boys than girls tend to accept the hero's behavior in highlighting the neutral intent, personal force lead to harm results.Meanwhile, in highlighting the negative intentions, personal force caused harm results, the subjects who are more sad emotional experience incline to accept the hero's behavior, but also easier to utilitarian moral judgments.But the subjects who are fewer sad emotional experience are more inclined to carry out non-utilitarian moral judgments. This may be that the subjects of less sad emotional experience don't experience a sense of sadness at the expense of many lives, only to make a non-utilitarian moral judgments; and the subjects of more a sense of sadness are relatively easy to realize the sadness of sacrifice more life,so they agree to sacrifice one's life to save the lives of more people. These conclusions are more intuitive to show the relationship between emotions and moral judgment, but also provides a theoretical guidance for emotional education and moral education of college students.

\section{References}

[1] Blanchard-Fields, F., \& Coats, A. H. (2008). The Experience of Anger and Sadness in Everyday Problems Impacts Age Differences in Emotion Regulation. Development Psychology, 44 (6) 1547-1556.

[2] Greene, J. D., Nystrom, L. E., Engell, A. D., Darley, J. M., \& Cohen, J. D.(2004). The neural bases of cognitive conflict and control in moral judgment. Neuron, 44(2), 389-400.

[3] Greene, J. D., Cushman, F. A., \& Cohen, D. J. (2009). Pushing moral buttons: The interaction between personal force and intention in moral judgment. Cognition, 111, 364-371.

[4] Birditt, K. S., \& Fingerman, K. L. (2005). Do we get better at picking our battles? Age group differences in descriptions of behavioral reactions to interpersonal tensions. Journals of Gerontology, Series B: Psychological Sciences and Social Sciences, 2005, 60, 121-128.

[5] Shuliang Mo,Kui Sun, Zongkui Zhou .(2011).Experience sadness and emotion regulation strategies of older people in daily solving interpersonal problems: the role of age and personality traits. Psychological Science34(6):111 116.

[6] Cushman, F. (2008). Crime and punishment: Distinguishing the roles of causal and intentional analyses in moral judgment. Cognition, 108 , 353-380. 


\section{Annex 1: four kinds of stories with different content}

\section{impersonal forces caused injury situation}

An empty runaway trolley is speeding down a set of tracks toward five railway workmen. If nothing is done, the trolley will proceed down the main tracks and cause the deaths of the five workmen.There is a circular track which is between trolley and 5 workers connecting the main track. A railway workman is maintaining railway on the circular track

\section{Negative intent,impersonal forces:}

Li Gang saw the entire incident, he thought that if he pulled the turn switch, the trolley will turn to a circular orbit, crashed into the heavy load of workers, the trolley will stop. Thus, Li Gang pulled the switch, so that the trolley turned circular orbit, crashed into that worker and stopped.

\section{Neutral intent,impersonal forces :}

Meanwhile, there is heavy box which is placed far behind that worker on the circular orbit.Li Gang believes that if he pulled the turn switch, trolley will turn the circular track, hit the heavy box, the trolley will stop, but the trolley will not hit the worker.Thus, Li Gang pulled the switch, so the trolley turned circular orbit, trolley hit the worker and box and stopped.

\section{personal forces caused injury situation}

An empty runaway trolley is speeding down a set of tracks toward five railway workmen. There is a foot-bridge above the tracks in between the runaway trolley and the five workmen. On this footbridge there is a railway workman wearing a large, heavy backpack. This worker stand between turning the switch and the Li Gang. If nothing is done, the trolley will proceed down the main tracks and cause the deaths of the five workmen .

\section{Negative intent,personal forces:}

Li Gang saw the entire incident, he thought that if he pulled quickly turn the switch, he have to push the worker standing in the middle of bridge. Thus, Li Gang pushed the worker down the bridge and timely moved the switch.

\section{Neutral intent,personal forces:}

Li Gang saw the entire incident, he thought that if he pulled quickly turn the switch, he didn't push the worker standing in the middle of bridge. Thus, Li Gang pushed the worker down the bridge and timely moved the switch.

question:

1、Do you think the Li Gang's such behavior is morally acceptable? yes or no.

2、If you think the Li Gang's behavior is morally acceptable, judge at 7 rate scale. 